\title{
REDISCOVERY OF THE ENDANGERED FOREST SPIKETHUMB FROG PLECTROHYLA GLANDULOSA (HYLIDAE) AT A MODERATELY DISTURBED BREEDING SITE IN THE HIGHLANDS OF GUATEMALA, CENTRAL AMERICA REDESCUBRIMIENTO DE LA RANA PLECTROHYLA GLANDULOSA (HYLIDAE) EN UN SITIO DE REPRODUCCIÓN MODERADAMENTE PERTURBADO EN LAS TIERRAS ALTAS DE GUATEMALA, CENTRO AMÉRICA
}

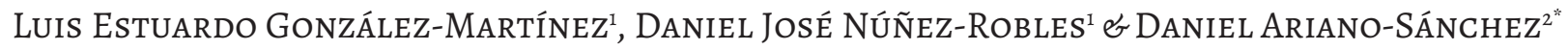 \\ ${ }^{1}$ Departamento de Biología, Universidad del Valle de Guatemala, Guatemala City, Guatemala. \\ ${ }^{2}$ Centro de Estudios Ambientales y Biodiversidad, Universidad del Valle de Guatemala, Guatemala City, Guatemala. \\ Correspondence: dariano@uvg.edu.gt \\ Received: 2020-08-28. Accepted: 2020-12-10.
}

Plectrohyla glandulosa is an endangered species of streambreeding frog, previously reported only from well-preserved fir forest, pine-cypress forest, and montane grasslands (Acevedo \& Smith, 2004). This species is considered as a priority for conservation efforts because of its medium vulnerability and distribution restricted to a single physiographic region (MataSilva et al., 2019). This species is known only from the Sierra de los Cuchumatanes and the central and southern highlands of Guatemala at a range of $2400-3500$ m elevation (Wilson et al., 2010). Herein, we present the first record in more than 30 years for this species from the lagoon of Chicabal volcano, an historical breeding site for this species in Guatemalan highlands. The photographic vouchers of the specimen were deposited at the Digital Collection of the University of Texas at Arlington (UTADC). Jonathan Campbell did the taxonomic verification of the specimen.

On 17 August 2018, at 2000h, an adult P. glandulosa (UTADC $9630 \mathrm{a}$; Fig. 1A) was found approximately $1 \mathrm{~m}$ above the ground, in a branch of a standing dead tree located in the tourist trail that surrounds the south western margins of the lagoon located in the crater of Chicabal volcano (Fig. 1B), San Martín Sacatepéquez, Quetzaltenango, Guatemala $\left(14.78584^{\circ} \mathrm{N}, 91.65672^{\circ} \mathrm{W}\right.$, WGS $84,2700 \mathrm{~m}$ elev.). This site is more than $3 \mathrm{~km}$ from the nearest stream.

The last specimens seen on the lagoon margins were recorded in 1976 by Theodore Papenfuss (CAS: HERP: 143025). Exotic carp (Cyprinus carpio) were introduced in the Chicabal lagoon in the 1980 s and they probably have decimated anuran populations at the site, as they are known to cause such effects in other anuran populations (Kloskowski, 2011). Chicabal lagoon is now part of the Chicabal volcano protected area (Fig. 2) in the

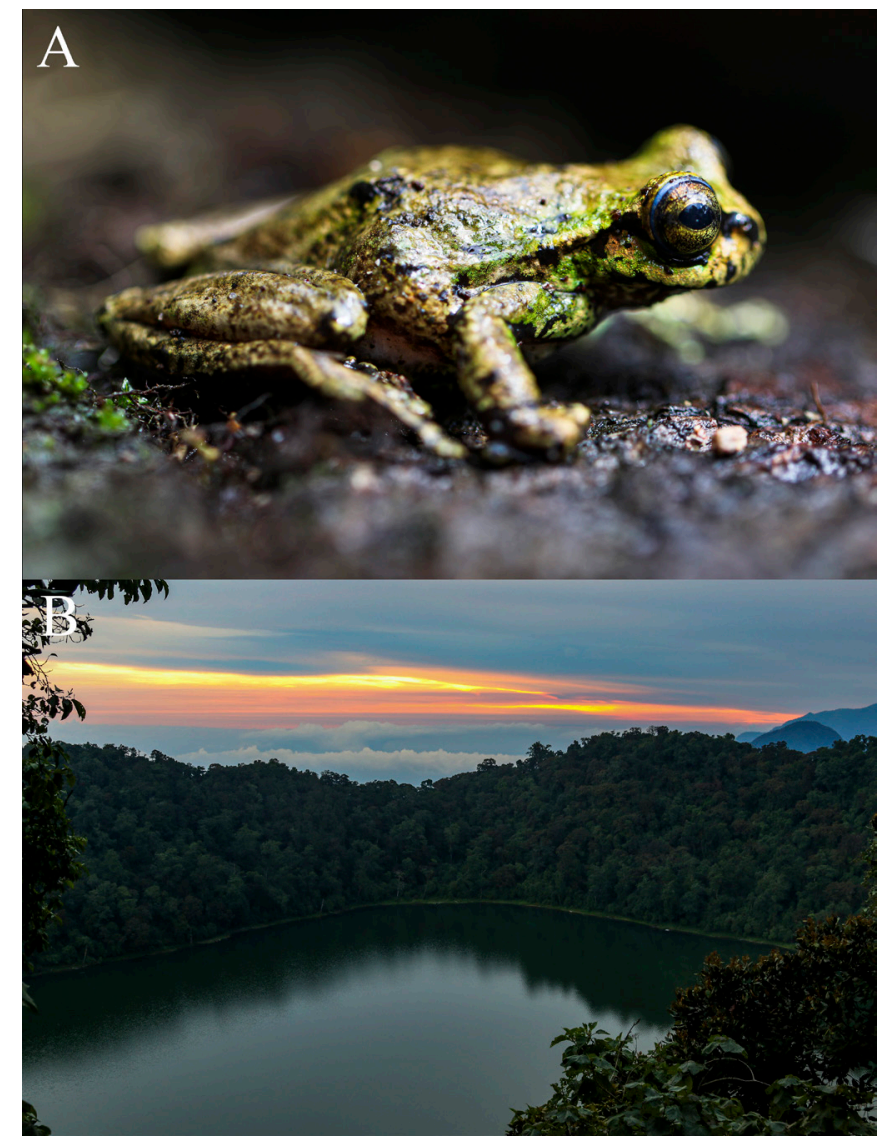

Figura 1. Plectrohyla glandulosa encontrada el 17 de Agosto 2018 (A) en los márgenes de la laguna ubicada en el cráter del volcán Chicabal (B) a una elevación de 2700 m, Quetzaltenango, Guatemala. Fotos: D. Nuñez-Robles.

Figure 1. Plectrohyla glandulosa found on 17 August 2018 (A) in the margins of the lagoon at the crater of Chicabal volcano (B) at 2700 m elevation, Quetzaltenango, Guatemala. Photo: D. Nuñez-Robles. 
Guatemalan highlands (Consejo Nacional de Áreas Protegidas 2016). The site where the specimen was found is disturbed due to tourism and traditional Mayan religious activities, representing a confirmation that the species can survive in moderately disturbed habitats.

Acknowledgments. - We thank Hellen Dahinten and the students of the Ecology course from Universidad del Valle de Guatemala for their help in the search of amphibians during the field trip. ASAECO and CONAP provided permits to conduct the scientific research at the reserve. The field research was supported by Departamento de Biología, Universidad del Valle de Guatemala. Thanks to Gregory Pandelis for his support adding the photographic vouchers to the University of Texas at Arlington Digital Collection. Thanks to Sean Rovito and an anonymous reviewer for valuable comments that had improved our manuscript.

\section{CITED LITERATURE}

Acevedo, M. \& E. Smith. 2004. The IUCN Red List of Threatened Species 2004: e.T55875A11367111.https://dx.doi.org/10.2305/
IUCN.UK.2004.RLTS.T55875A11367111.en. Downloaded on 27 August 2020.

Consejo Nacional de Áreas Protegidas. 2016. Plan Maestro de la Zona de Veda Definitiva Volcán Chicabal, San Martín Sacatepéquez, Quetzaltenango. CONAP. 128 p.

Kloskowski, J. 2011. Impact of common carp Cyprinus carpio on aquatic communities: direct trophic effects versus habitat deterioration. Fundamental and Applied Limnology 178: 245-255.

Mata-Silva, V., D.L. DeSantis, E. García-Padilla, J.D. Johnson \& L.D. Wilson. 2019. The endemic herpetofauna of Central America: A casualty of anthropocentrism. Amphibian \& Reptile Conservation 13:1-64.

Wilson, L.D., J.A. Townsend \& J.D. Johnson. 2010. Conservation of Mesoamerican Amphibians and Reptiles. Eagle Mountain Publishing. 812 p.

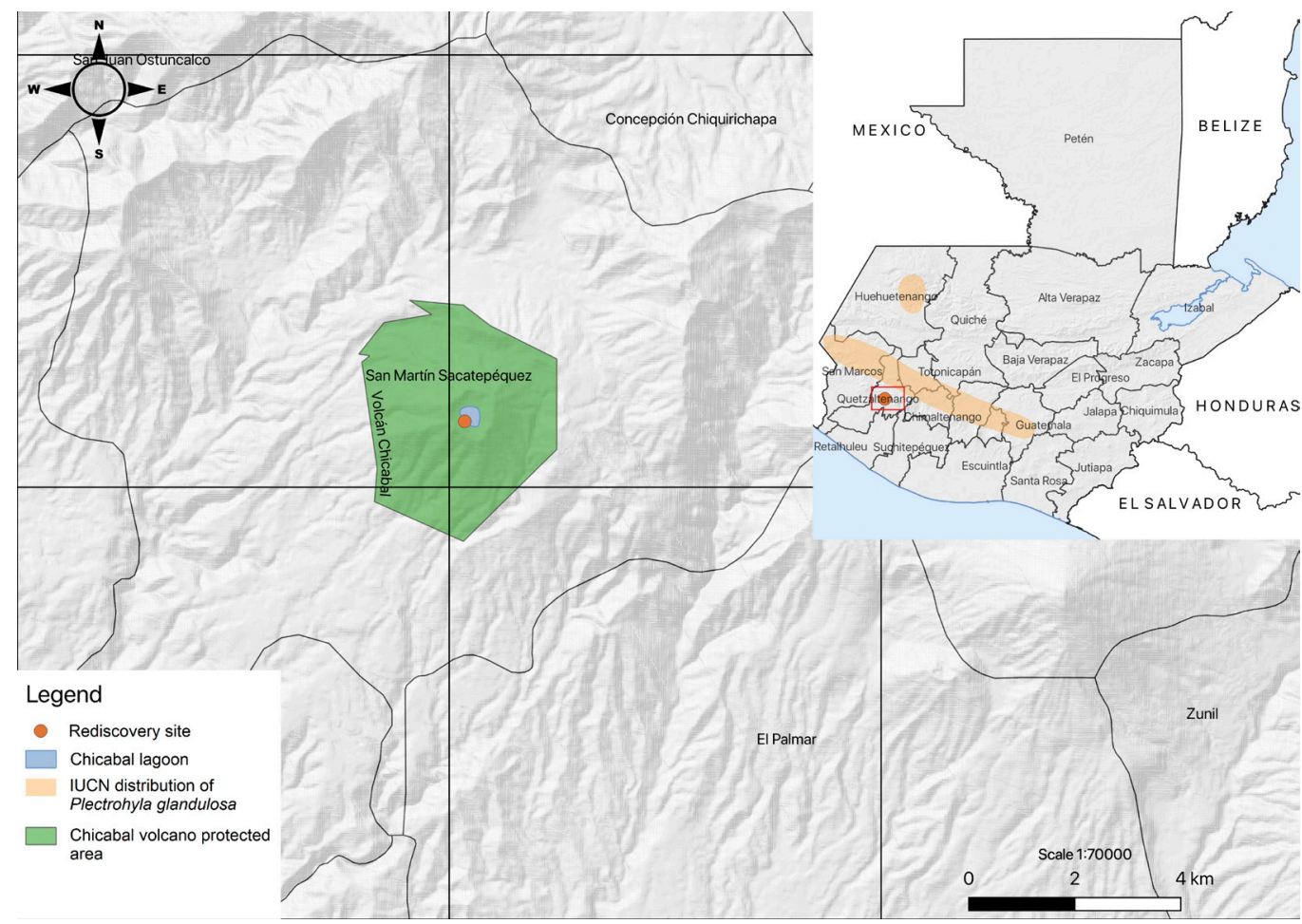

Figura 2. Mapa de la localidad de avistamiento de Plectrohyla glandulosa dentro del área protegida de volcán Chicabal, Quetzaltenango, Guatemala.

Figure 2. Map of the location of the sighting of Plectrohyla glandulosa within the Chicabal volcano protected area, Quetzaltenango, Guatemala. 